
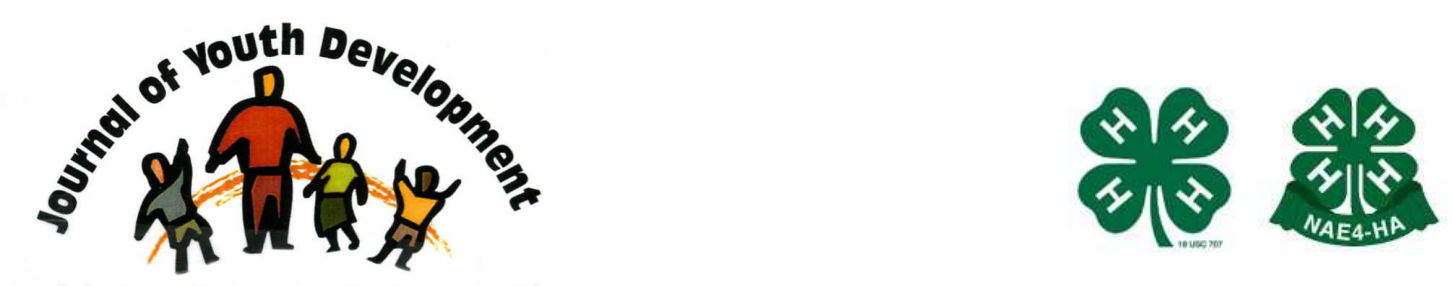

Bridging Research \& Practice

\title{
Assessing Rural Communities through Youth Photography
}

\author{
Renee A. Oscarson \\ South Dakota State University \\ Renee.Oscarson@sdstate.edu \\ Mary T. Bowne \\ South Dakota State University \\ Debra A. DeBates \\ South Dakota State University \\ Julie A. Bell \\ South Dakota State University \\ Sherri S. Bair \\ South Dakota State University
}




\title{
JOURNAL OF YOUTH DEVELOPMENT \\ bridging research and practice

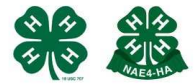

Volume 7, Number 2, Summer 2012

Article 120702RS004

\section{Assessing Rural Communities through Youth Photography}

\author{
Renee A. Oscarson, Mary T. Bowne, Debra A. DeBates, Julie A. Bell and Sherri S. Bair \\ South Dakota State University
}

\begin{abstract}
Despite frequent concerns about youth and young adult migration from rural to urban areas, most measures used to assess youth in rural community research have been developed by adults. Accurate understanding of youth community perceptions necessitates youth input into the research process. The participatory research strategy described here, using photography to describe community, enables youth to define community and identify what they value about their communities.

Photographs and explanations of the photographs indicated that youth value places (schools, churches, as well as locations unique to communities) and people from those communities. Photovoice, photography-based participatory-action research, is a feasible and engaging method for obtaining youth perspectives on community issues. Further, Photovoice may be adapted to the needs of different age groups and situations.
\end{abstract}

\section{Introduction}

Adolescents are impacted by experiences within their communities (Vieno, Santinello, Pastore, \& Perkins, 2007) and benefit from having voice in their community decisions (Evans, 2007). Rural youth frequently leave their communities for college and/or jobs. A sense of connectedness to a "home" community may lead some eventually to return. In an era characterized by declining rural populations, many rural community leaders are concerned about youth remaining in or returning to communities.

Rural to urban migration of youth and young adults has contributed to declining rural populations and has concerned researchers for decades (e.g., Beauford, 1989; Huang, Weng, Zhang, \& Cohen, 1997). High school seniors' intentions related to remaining in versus leaving 
small towns have been associated with job opportunities and educational goals, as well with social ties (Kirkpatrick Johnson, Elder, \& Stern, 2005). Lack of educational and occupational opportunities alone may not explain some young people's decisions to leave rural communities. Based on a study of rural Australian youth, researchers suggested that future studies related to youth migration and retention also examine community sentiment, including belonging, sense of community and social support (Pretty, Bramston, Patrick, \& Pannach, 2006).

Although the benefits of youth involvement for both youth and communities are acknowledged, most measures to assess community have been developed by researchers who have sought to identify important components of community. After measures are validated, youth participants in community research typically respond to questions regarding concerns identified by adults. Addressing youth views of community, however, necessitates some input by youth into the research process. Participatory action research allows participants to be involved in identifying research issues.

The qualitative, participatory research strategy described here, using photography to describe community, was part of a larger project examining community attachment among rural youth and older adults. The purpose of this portion of the study was to examine youth perspectives on community, identifying what they valued most about their communities. Because schools are a location where most youth in a community gather, the procedure was designed to be used as part of curriculum on "community" or as an activity for a high school co-curricular organization, while simultaneously gaining information about communities through the eyes of youth.

\section{Procedure}

Participant schools were recruited during a brief training on intergenerational service-learning activities for middle school and high school Family, Career, and Community Leaders of America (FCCLA) advisors. Four advisors and their students participated in the project. The sample consisted of 32 students, 11 males and 21 females ranging from 15 to 18 years old, from communities with populations of 400 to 14,000 (three communities with several hundred and one with 14,000). Because participating FCCLA advisors completed the intergenerational service-learning activity either with one class or attendees at a chapter meeting and because some rural schools have very small class sizes, the total sample size is small.

The focus of the activity was on photographing community features viewed as important by the youth participants. The photography technique was adapted from the Photovoice method developed by Caroline Wang and first used among village women in China's Yunnan Province (Wang, Yi, Tao, \& Carovano, 1998). Based on critical and feminist theories, Photovoice provides participants the opportunity to identify issues of importance via photographing components of their own lives (See www.photovoice.com for further information and research using Photovoice, (Wang, 2005).

The Photovoice method was adjusted for the realities of classroom/organization time limitations, camera availability and developmental levels of the participants. Each student was given instructions to think of places or people in the community that were important to him or her, to develop a list of the places or people, and to circle the three that were most important to him or her as an individual. After discussing the ethics of photography (e.g., respecting privacy, obtaining permission) students left the school in small groups to photograph what they had identified as important. Disposable cameras were made available to those who wanted them, 
but most advisors/teachers chose to use digital cameras. Upon return to the classroom, students described their photographs, explored why the photos were meaningful, and answered the question "What does 'community' mean to you?"

Students recorded their discussion responses on worksheets. Worksheets and 103 corresponding photos were submitted to two of the researchers (Bair and Bowne) for further analysis. The researchers examined the photos and written responses for themes, both within and among schools. After reviewing the material and tallying identified themes, results were compared to determine inter-rater reliability $(\alpha=.95)$ in categorizing photographs as places, things, or people.

\section{Results}

Places in communities were most frequently photographed by youth; $62 \%$ of the photos were of community places. Although schools and churches frequently were photographed, specific places identified as important appeared to be related to what places or services were located in or available to each of the communities. Places unique to each community were photographed by students in that community. For example, one community has a museum, another has a bank, and another has a local grocery and convenience store. The majority of the photographs, however, were of churches and schools, all of which were prevalent within the smaller communities. The photos did include pictures of outdoors and recreation. One male and one female each photographed a dog, and four others photographed nature-related scenes. Over fifty percent of students indicated that places in which people in their community gathered gave them a sense of belonging.

Youth also recognized people as important to their communities. Two-thirds (21) of the students included people in their photos, even though taking pictures of people required additional steps to obtain permission. Those people included friends, family members, and community members such as teachers, principals, and pastors. Students' written responses also indicated that people were important. For example, definitions of community included, "A group of people willing to step forward in times of need and support," "a place where people care for each other" and "a place where people can encourage one another."

Although the sample size was not large enough to draw definitive conclusions about gender differences, students did take pictures of things, two took pictures of cars and one of a stereo. Two females took pictures of Bibles and one of a Christmas tree. Nevertheless, tallies of the photos into categories of places, people, and things and an examination of written responses explaining the photos indicate that places were more evident than things in what youth identified as important in their communities.

\section{Discussion and Conclusions}

The results of this study suggest that characteristics of community identified as important by youth may be the same features adults consider important. We suspect that community leaders would be proud of students' definitions of community and pleased to see what they identified as important. This strategy may be used as a community development tool to help citizens of all ages recognize what they value in their communities, and to identify those features or characteristics which might be used as incentives for youth to return to rural communities. 
Photography is an engaging way to involve youth in participatory action research. Taking pictures allows students with varying literacy skills to express their values and concerns. In addition to minimizing literacy-related barriers related to surveys, photography involves more action, and thus, greater potential for engagement in the research process. Moreover, participants who take photographs are allowed to define research issues and thus, have a greater voice in community direction.

The process and results of this study lead to several recommendations for future studies. First, we recommend that more emphasis be placed on gathering data from more participants in one or two communities. Because the sample sizes from individual communities were not sufficient to draw conclusions about specific communities or to compare communities, data are described for the group as a whole. Rather than contacting FCCLA advisors from multiple schools, the results may have been more useful if we had worked with leaders of multiple youth groups within a community.

Future studies also would benefit from an "objective" list (perhaps a checklist provided to youth group advisors) of community resources, the location of students when the activity was conducted, and whether or not students had access to transportation when they were taking photographs. For example, many rural communities have lost post offices, banks, museums, and grocery stores. Our research illustrates that students in small communities (rightfully) value the banks, museums, and convenience stores that remain in their communities. In communities where these resources are less scarce, the results may differ considerably.

Adaption of the Photovoice methodology allowed us to provide a classroom/FCCLA activity that also provided preliminary information about youth impressions of their communities. After carefully examining the data, we recommend using similar research as a preliminary activity to connect with schools and identify potential community strengths or challenges that would lead to thorough utilization of the Photovoice methodology.

As a participatory action research method, Photovoice can be used to bring about youth-led community change (e.g., Brazg, Bekemeier, Spigner, \& Huebner, 2011). An additional benefit is that, although "shortcuts" may decrease benefits, it may be adapted to suit the needs of various situations. Decreasing costs of digital cameras and increasing use of cell phones with digital cameras make a photography-based participatory-action research a feasible method for obtaining youth perspectives on community issues.

\section{References}

Beauford, E.Y. (1989). Revitalizing rural America: Focus on rural youth. Southern Rural Sociology, 6, pp. 1-11.

Brazg, T., Bekemeier, B. Spigner, C., \& Huebner, C.E. (2011). Our community in focus: The use of Photovoice for youth-driven substance abuse assessment and health promotion. Health Promotion Practice, 12:4, pp. 502-511.

Evans, S.D. (2007). Youth sense of community: Voice and power in community contexts. Journal of Community Psychology, 35:6, pp. 693-709. 
Huang, G.G., Weng, S., Zhang, F., \& Cohen, M.P. (1997). Outmigration among rural high school graduates: The effect of academic and vocational programs. Educational Evaluation and Policy Analysis, 19:4, pp. 360-372.

Kirkpatrick Johnson, M., Elder, G.H., \& Stern, M. (2005). Attachments to family and community and the young adult transition of rural youth. Journal of Research on Adolescence, 15:1, pp. 99125.

Pretty, G., Bramston, P., Patrick, J., \& Pannach, W. (2006). The relevance of community sentiments to Australian rural youths' intention to stay in their home communities. American Behavioral Scientist, 50:2, pp. 226-240.

Vieno, A., Santinello, M., Pastore, M., \& Perkins, D.D. (2007). Social support, sense of community in school, and self-efficacy as resources during early adolescence: An integrative model. American Journal of Community Psychology, 39:1/2, pp. 177-190.

Wang, C.C. (2005). Photovoice: Social change through photography. Available online at: www.photovoice.com

Wang, C.C., Yi, W.K., Tao, Z.W., \& Carovano, K. (1998). Photovoice as a participatory health promotion strategy. Health Promotion International, 13:1, p. 75.

(C) Copyright of Journal of Youth Development $~$ Bridging Research and Practice. Content may not be copied or emailed to multiple sites or posted to a listserv without copyright holder's express written permission. However, users may print, download or email articles for individual use. 